\title{
ESTUDO HIDROQUÍMICO E ISOTÓPICO DAS ÁGUAS SUBTERRĀNEAS NA REGIÃO DE RIBEIRÃO PRETO (SP)
}

\author{
GILBERT GALLO* e OSMAR SINELLI**
}

\begin{abstract}
The article starts with a brief account of the geological and hidrogeological characteristics of the Ribeirão Preto region. The feeding, circulation and behaviour of the groundwater are studied by means of geochemistry and environmental isotopes which, used in a complementary way, lead to conclusions which could not be reached with either method used independently.
\end{abstract}

INTRODUÇÃO O progresso econômico alcançado pela região de Ribeirão Preto no Estado de São Paulo tem provocado um considerável aumento na exploração de suas águas subterrâneas. Nessas condições e na falta de uma legislação capaz de planificar e controlar a utilização dos recursos hídricos subterrâneos, novas técnicas de estudo têm sido aplicadas no sentido de contribuir para um melhor conhecimento dos recursos hidricos. Neste trabalho, ênfase especial foi dada à parte hidroquímica, bem como à utilização de análises isotópicas com os seguintes objetivos:

- caracterização do aquijfero em função da rocha-reservatório

- características da recarga do aquiffero

- comportamento e evolução do aquífero.

\section{LOCALIZAÇÃO - FISIOGRAFIA E RELE-} VO A região estudada, com uma superfície de 1.500 $\mathrm{km}^{2}$, está situada a $300 \mathrm{~km}$ do $N N W$ da cidade de São Paulo (Fig. 1). A altitude regional é da ordem de 550 a $600 \mathrm{~m}$, com relevo levemente ondulado acompanhando o rebordo das escarpas basálticas. A drenagem é realizada principalmente pelos rios Pardo e Mogi Guaçu com os respectivos afluentes, que se dirigem para oeste e noroeste em busca do Rio Grande. Os rios correm, em parte sobre basaltos e em parte sobre sedimentos da Formação Botucatu, apresentando, algumas vezes, traçados

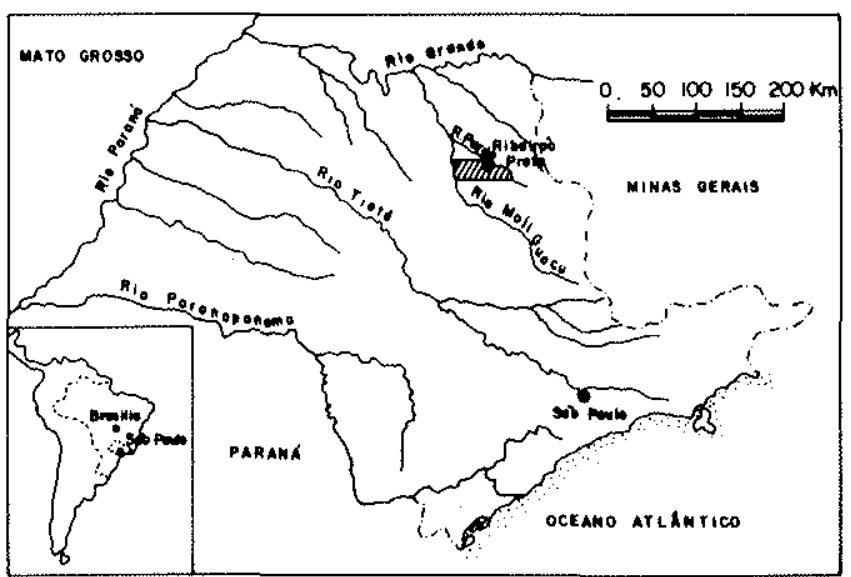

Figura 1 - Mapa de localização ortogonais e bem encaixados, indicando rejuvenescimento. A vegetação original era de mata foliada e atualmente está praticamente toda cultivada (café, cana, milho, soja, algodão).

CLIMA A região está situada na zona intertropical, apresentando um clima de transição, com inverno seco e verão úmido. De acordo com Setzer (1966), o clima pode ser classificado como do tipo Aw (Köppen). A temperatura média anual se situa entre 21 e $22^{\circ} \mathrm{C}$. A média dos meses chuvosos (verão) varia de 22 a $25^{\circ} \mathrm{C}$. A dos meses mais frios (junlo e julho) é próxima de 17 a $18^{\circ} \mathrm{C}$. O valor máximo absoluto pode ultrapassar $35^{\circ} \mathrm{C}$ e o mínimo pode ser inferior a $5^{\circ} \mathrm{C}$. O ciclo hidrológico, obtido com dados referentes a 28 anos (1943-1971), pode ser avaliado pela Fig. 2 .

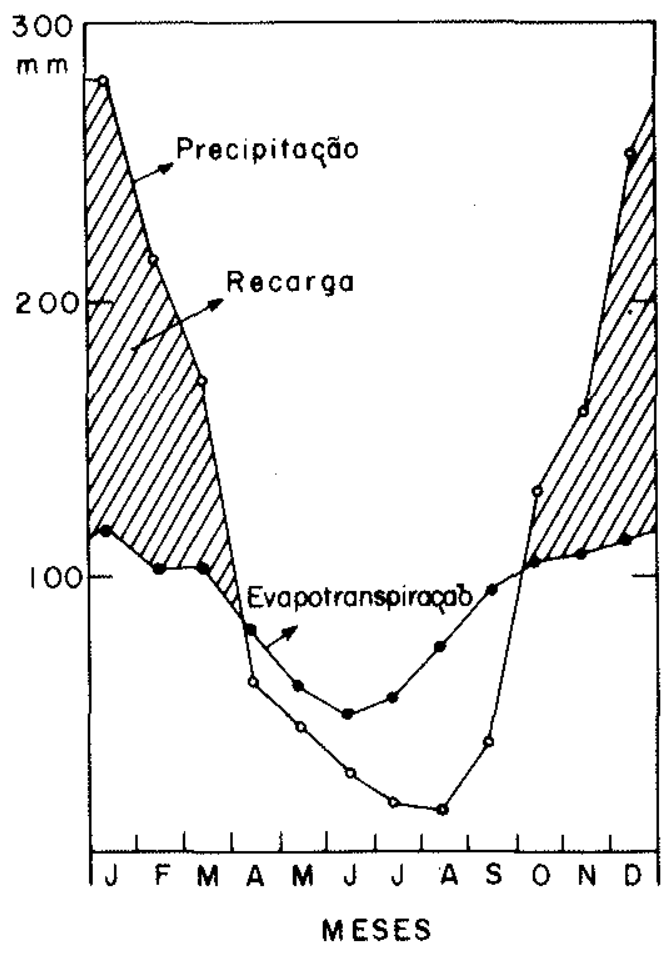

Figura 2 - Ciclo hidrológico da região (dados de 1943-71)

* Centre National de la Recherche Scientifique - Paris.

** Faculdade de Filosofia, Ciências e Letras de Ribeirão Preto - USP, Ribeirăo Preto (SP). 
GEOLOGIA E HIDROGEOLOGIA A região em questão faz parte da borda leste da Bacia Sedimentar do Paraná. O Mesozóico apresenta-se melhor desenvolvi do, com as Formações Pirambóia, Botucatu e Serra Geral. Os sedimentos Cenozóicos existentes constituem depósitos transitórios de ciclos erosivos mais duradouros e em processamento.

Formação Pirambóia e Botucatu (Ki-J) A Formação Pirambóia (Soares, 1973) corresponde a arenitos depositados em ambiente fluvial, com granulação variável de muito fina a média, com teor de argila variando de 10 a $20 \%$. Sua espessura na região é em torno de $100 \mathrm{~m}$. A Formação Botucatu é caracterizada por arenitos de granulação média a fina, estratificação cruzada de médio a grande porte, friáveis e de origem eólica, podendo, entretanto, apresentar fácies torrencial e lacustre. A espessura na região considerada é da ordem de $120 \mathrm{~m}$. Quanto às características hidrogeológicas, os dados obtidos não permitem uma separação das Formações Pirambóia da Botucatu. Nessas condições, os valores aqui mencionados (DAEE, 1974) envolvem praticamente as duas formaçðes (Fig. 3). A transmissividade varia de 250. a $300 \mathrm{~m}^{2} / \mathrm{d}$. O valor médio da permeabilidade para o arenito Botucatu foi de $3,5 \mathrm{~m} / \mathrm{d}$.

Formação Serra Geral (K-J) A formação é caracterizada por sucessivos derrames de basalto, cuja espessura é variável e em geral aumenta de leste para oeste. Em Ribeirão Preto, face à presença de corpos intrusivos (sills), os valores de espessura variam localmente de 18 a $120 \mathrm{~m}$. Na cidade de Sertãozinho, a espessura é da ordem de $100 \mathrm{~m}$ e na cidade de Barrinha o valor médio foi de $250 \mathrm{~m}$. O aquíífero nesta formação está condicionado às fraturas existentes. Valores regionais (DAEE, op. cit.) deram uma média para a transmissividade de $20 \mathrm{~m}^{2} / \mathrm{d}$ com uma porosidade efetiva de 1 a $5 \%$.
Composição mineralógica e química Essas rochas (extrusivas e intrusivas) são ricas em plagioclásios cálcicos (labradorida), piroxênios (augita e pigeonita) contendo quantidades importantes de ilmenita e titano-magnetita. Os minerais acessórios são vários e representados por quartzo, apatita, feldspatos alcalinos, olivina, hornblenda, biotita e minerais do grupo da clorita e serpentina. Análise modal efetuada (Melfi, 1967), apresenta os seguintes resultados: plagioclásio - 40 a $60 \%$; piroxênio - 25 a $40 \%$; magnetita e ilmenita $-10 \%$; apatita, quartzo e feldspato potássico - 0 a $2 \%$; clorita, biotita e anfíbólios no máximo $5 \%$.

A composição química dessas rochas foi estudada em detalhes (Ruegg, 1969). Apresentam a seguinte média em $\%$ para a região:

\begin{tabular}{ccccccccccc}
$\mathrm{SjO}_{2}$ & $\mathrm{Al}_{2} \mathrm{O}_{3}$ & $\mathrm{TiO}_{2}$ & $\mathrm{Fe}_{2} \mathrm{O}$ & $\mathrm{FeO}$ & $\mathrm{MnO}$ & $\mathrm{MgO}$ & $\mathrm{CaO}$ & $\mathrm{Na}_{2} \mathrm{O}$ & $\mathrm{K}_{2} \mathrm{O}$ & $\mathrm{P}_{2} \mathrm{O}_{6}$ \\
\hline 48,9 & 14,6 & 3,0 & 4,3 & 9,8 & 0,24 & 4,4 & 8,7 & 2,5 & 1,0 & 0,4 \\
\hline
\end{tabular}

Solos A análise mineralógica dos basaltos mostra que $70 \%$ são constituídos essencialmente por plagioclásios e piroxênios, minerais de relativa instabilidade. Sob a ação do clima tropical a alteração é bastante acentuada, intensa e rápida, apresentando, como resultado em certos locais, solos com espessuras de 20 a 45 metros. São solos caracterizados como ferralíticos, mostrando um enriquecimento em óxidos de ferro e titano.

Moniz (1967) analisando a fração argilosa de solo da região indica a seguinte composição: na fração argilosa fina o predomínio é do argilo-mineral caolinita ( 30 a $46 \%$ ), seguida por alophana (23 a $30 \%)$; argilo-minerais neoformados, micas $(15$ a $20 \%)$ e por último gibsita $(8$ a $10 \%)$, nos horizontes A e B.

No horizonte $C$, representado convencionalmente por rocha em alteração, a porcentagem de caolinita decresce a $21 \%$ e a de gibsita para $1 \%$. Já o grupo das mi-

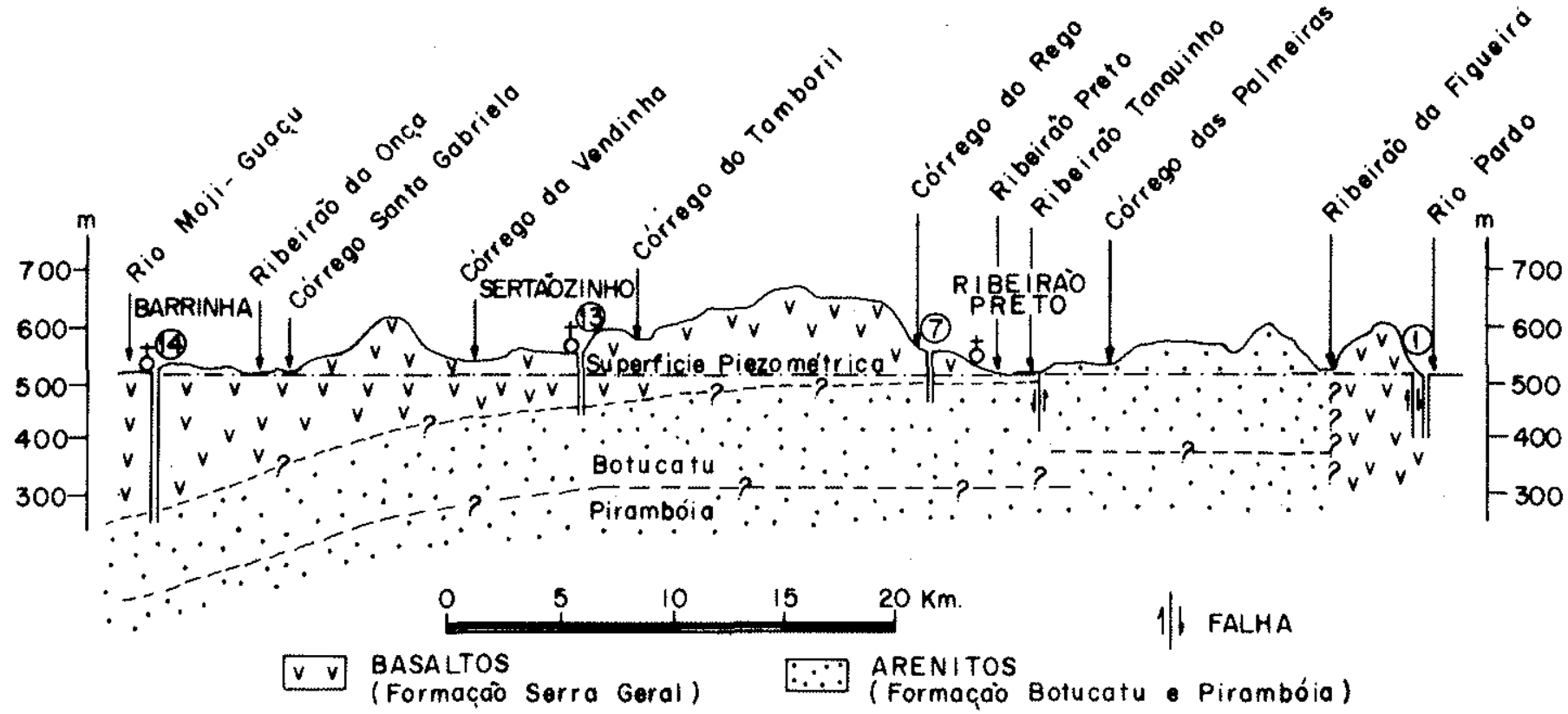

Figura 3 - Perfil geológico 
cas (Illitas) passam a 55\%. As illitas de neoformação representam uma fase intermediária de alteração dos alumínio-silicatos primários em caolinita e gibsita. A Fig. 4 mostra uma comparação entre a composição da rocha e do solo.

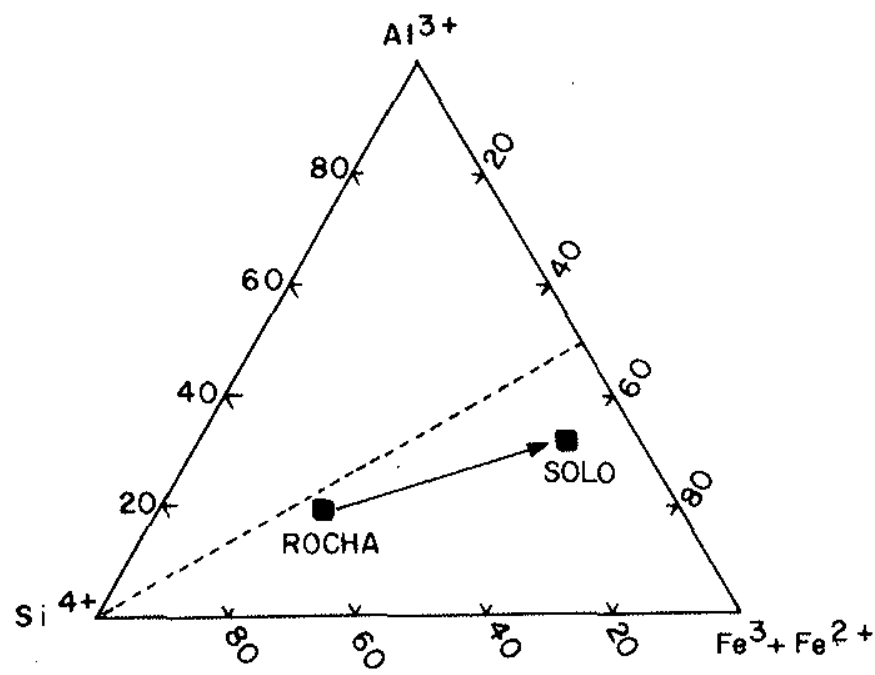

Figura 4-Composição relativa em $\mathrm{Si}, \mathrm{Al}, \mathrm{Fe}$ entre a rocha e o solo

ESTUDO GEOQUIMMICO O estudo geoquímico das águas subterrâneas foi realizado a partir dos resultados obtidos na análise de 16 amostras, de tal forma que pudesse ser representativo da região em estudo. Nessas condições, a amostragem foi obtida de: poços tubulares perfurados no basalto, poços tubulares perfurados no Arenito Botucatu, poços tubulares perfurados no Basalto + Arenito Botucatu, fonte no Basalto e amostra de água fluvial retirada do Rio Pardo.

Os valores do $\mathrm{pH}$ e temperatura, fatores fundamentais para o equilíbrio químico, foram determinados no campo. Resistividade, $\mathrm{CO}_{2}$ livre e bicarbonatos foram determinados no máximo 4 horas após a coleta em laboratório. As amostras foram recolhidas em frascos de poliestireno com vedação total. $\mathrm{CO}_{2}$ livre, $\mathrm{HCO}_{3}^{-} \mathrm{e}$ $\mathrm{Cl}^{-}$foram determinados volumetricamente. Os elementos $\left(\mathrm{Ca}^{2+}, \mathrm{Mg}^{2+}, \mathrm{Na}^{+}\right.$e $\left.\mathrm{K}^{+}\right)$foram determinados por espectrofotometria de absorção atômica e os elementos menores $\left(\mathrm{Fe}^{2+}, \mathrm{Fe}^{3+}, \mathrm{Al}^{3+}, \mathrm{Ti}^{4+}\right)$ por colorimetria. A sílica $\left(\mathrm{SiO}_{2}\right)$ foi determinada colorimetricamente. As características dos poços estão na Tab. 1, os parâmetros físico-químicos na Tab. 2 e as análises químicas na Tab. 3.

Interpretação dos dados geoquímicos A temperatura é praticamente homogênea para todas as amostras $\left(25^{\circ} \mathrm{C}\right)$, exceção é feita no poço n: 14 onde os $31^{\circ} \mathrm{C}$ se devem provavelmente ao gradiente geotérmico.

$\mathrm{O}$ pH das águas varia de 5,6 a 8,1 . A maioria dos valores situam-se entre 6 e 6,5; valor normal para águas que percolam arenitos e rochas ígneas fraturadas. Três amostras apresentam $\mathrm{pH}$ superior a 7, ou seja, a amostra do Rio Pardo e dos poços 13 e 14 situados a oeste do aquíf fero. $O$ estudo geoquímico mostrará que a evolução do aquiifero explica esse aumento do $\mathrm{pH}$, bem como o estudo isotópico indicará o sentido de circulação de leste para oeste.

Todas as amostras são pouco mineralizadas, apresentando valores de $27 \mathrm{mg} / \mathrm{l}$ (leste) a $163 \mathrm{mg} / \mathrm{l}$ (oeste). A condutividade aumenta de $20,4 \mu \mathrm{mho} / \mathrm{cm}$ para o poço n. 2 (arenito Botucatu) para $161,0 \mu \mathrm{mho} / \mathrm{cm}$ para o poço n. 13.

Em todas as amostras, os teores em alcalino-tẹrosos são superiores aos dos alcalinos; ou

$$
r \mathrm{Ca}+r \mathrm{Mg}>r \mathrm{Na}+r \mathrm{~K}
$$

$O$ indice $r$ (Schoeller, 1962) é devido à concentração em $\mathrm{meg} / \mathrm{l}$.

Os valores obtidos podem ser agrupados em 3 grupos que correspondem à posição geográfica dos poços:

Grupo 1: poços 4 a $9-r \mathrm{Ca}>r \mathrm{Mg}>r \mathrm{~K}>r \mathrm{Na}$

Grupo 2: poços 2, 10, 12, 15 (fonte) e 16 (Rio) $-r \mathrm{Ca}>$ $>r \mathrm{Mg}>r \mathrm{Na}>r \mathrm{~K}$

Grupo 3: poços 13 e $14-r \mathrm{Ca} \gg r \mathrm{Na}>r \mathrm{Mg}>r \mathrm{~K}$

Tabela 1 - Características dos poços amostrados

\begin{tabular}{|c|c|c|c|c|c|c|c|}
\hline № & Localizaçåo & Altitude & Prof. & N. Est. & Esp. basalto & E. arenito & Vazão $\mathrm{m}^{3} / \mathrm{h}$ \\
\hline 1 & Serrana & 515 & 117 & surg. & 0 & 117 & 120 \\
\hline 2 & Lagoinha & 590 & 105 & 10 & 0 & 105 & 50 \\
\hline 3 & Tanquinho & 513 & 75 & 10 & 0 & 75 & 70 \\
\hline 4 & Tanquinho & 519 & 150 & 18 & 0 & 150 & 100 \\
\hline 5 & Botafogo & 595 & 108 & 50 & 90 & 18 & 70 \\
\hline 6 & Mogiana & 524 & 107 & 21 & 80 & 27 & 80 \\
\hline 7 & Pompolo & 549 & 88 & 48 & 58 & 30 & 75 \\
\hline 8 & Via Café & 528 & 122 & 26 & 83 & 39 & 90 \\
\hline 9 & Sta. Teresa & 531 & 83 & 34 & 78 & 5 & 90 \\
\hline 10 & Sta. Teresa & 530 & 80 & 30 & 74 & 6 & 90 \\
\hline 11 & Medicina & 580 & 65 & & 65 & & 30 \\
\hline 12 & Bonfim & 550 & 85 & 27 & 85 & & 70 \\
\hline 13 & Sertãozinho & 540 & 112 & 45 & 80 & 12 & 90 \\
\hline 14 & Barrinha & 505 & 269 & surg. & 254 & 15 & 100 \\
\hline
\end{tabular}


Tabela 2 - Parâmetros físico-químicos

\begin{tabular}{rccc}
\hline N. & Temp. & pH & $\begin{array}{c}\text { Condutividade } \\
\text { umho } \cdot \mathrm{cm}^{-1} \\
25^{\circ} \mathrm{C}\end{array}$ \\
\hline ref. & ${ }^{\circ} \mathrm{C}$ & & 64,7 \\
1 & 25,0 & 6,20 & 22,8 \\
3 & 23,5 & 6,85 & 20,4 \\
4 & 25,0 & 5,60 & 29,2 \\
5 & 25,0 & 5,85 & 27,1 \\
6 & 23,8 & 6,05 & 38,6 \\
7 & 25,0 & 6,10 & 69,0 \\
8 & 26,0 & 6,20 & 54,6 \\
9 & 25,8 & 6,10 & 51,0 \\
10 & 25,0 & 6,10 & 81,9 \\
11 & 25,0 & 6,15 & 100,7 \\
12 & 26,5 & 6,30 & 158,0 \\
13 & 26,0 & 6,55 & 161,1 \\
14 & 26,0 & 7,70 & 149,6 \\
15 & 31,0 & 8,10 & 108,6 \\
16 & 22,0 & 6,40 & 42,4 \\
\hline
\end{tabular}

Tabela 3 - Composição química

\begin{tabular}{|c|c|c|c|c|c|c|c|c|c|c|c|c|c|}
\hline No: & $\begin{array}{l}\mathrm{Ca}^{2+} \\
\mathrm{ppm}\end{array}$ & $\begin{array}{l}\mathrm{Mg}^{2+} \\
\mathrm{ppm}\end{array}$ & $\begin{array}{l}\mathrm{Na}^{+} \\
\mathrm{ppm}\end{array}$ & $\begin{array}{c}\mathrm{K}^{+} \\
\mathrm{ppm}\end{array}$ & $\begin{array}{c}\mathrm{HCO}_{3}^{-} \\
\mathrm{ppm}\end{array}$ & $\begin{array}{c}\mathrm{Cl}^{-} \\
\mathrm{ppm}\end{array}$ & $\begin{array}{l}\mathrm{SO}_{-}^{-} \\
\text {ppm }\end{array}$ & $\begin{array}{l}\mathrm{NO}_{3}^{-} \\
\mathrm{ppm}\end{array}$ & $\begin{array}{c}\Sigma \text { cat. } \\
\text { meq } \cdot 1^{-1}\end{array}$ & $\begin{array}{c}\Sigma \text { ani. } \\
m e q \cdot 1^{-t}\end{array}$ & $\underset{\%}{\operatorname{diff} .}$ & $\begin{array}{l}\mathrm{SiO}_{2} \\
\text { ppm }\end{array}$ & $\begin{array}{c}\text { Miner. } \\
\text { ppm }\end{array}$ \\
\hline 1 & 5,1 & 1,2 & 4,0 & 5,0 & 37,4 & 1,5 & 0 & 0 & 0,655 & 0,654 & 0 & 23,0 & 77 \\
\hline 2 & 1,7 & 1,0 & 0,3 & 0,4 & 13,8 & 1,5 & 0 & 0 & 0,191 & 0,268 & 16,8 & 8,5 & 27 \\
\hline 3 & 1,1 & 0,8 & 0,5 & 3,1 & 12,6 & 1,5 & - & 0,1 & 0,223 & 0,248 & 5,3 & 18,5 & 38 \\
\hline 4 & 2,5 & 1,0 & 0,8 & 2,8 & 17,6 & 1,5 & 0 & 0,3 & 0,311 & 0,329 & 2,7 & 24,0 & 50 \\
\hline 5 & 3,4 & 1,2 & 0,3 & 1,4 & 15,0 & 2,0 & 0 & 0 & 0,318 & 0,302 & 2,6 & 21,5 & 45 \\
\hline 6 & 4,0 & 1,3 & 1,0 & 2,8 & 22,6 & 2,0 & - & 0,1 & 0,418 & 0,427 & 1,0 & 21,0 & 55 \\
\hline 7 & 6,1 & 1,6 & 1,7 & 3,8 & 34,6 & 1,5 & 0 & 0 & 0,608 & 0,608 & - & 25,0 & 75 \\
\hline 8 & 5,1 & 1,7 & 1,6 & 4,2 & 30,8 & 1,5 & 0 & 0 & 0,574 & 0,546 & 2,5 & 26,5 & 71 \\
\hline 9 & 4,6 & 1,5 & 1,5 & 3,0 & 31,4 & 1,5 & - & 0 & 0,493 & 0,557 & 6,0 & 25,5 & 69 \\
\hline 10 & 9,1 & 1,7 & 3,3 & 1,2 & 38,1 & 2,0 & 0 & 0,5 & 0,770 & 0,680 & 6,2 & 28,5 & 84 \\
\hline 11 & 8,6 & 2,2 & 2,8 & 4,0 & 59,7 & 1,5 & 0 & - & 0,834 & 1,020 & 10,0 & 30,5 & 109 \\
\hline 12 & 18,9 & 5,6 & 5,1 & 4,2 & 92,4 & 4,0 & 0 & 0,3 & 1,729 & 1,626 & 3,1 & 29,5 & 160 \\
\hline 13 & 24,0 & 1,6 & 5,3 & 3,4 & 99,3 & 4,0 & 0 & 0,1 & 1,650 & 1,740 & 2,7 & 25,5 & 163 \\
\hline 14 & 21,7 & 1,7 & 5,8 & 3,0 & 93,0 & 4,5 & 0 & 0,1 & 1,554 & 1,651 & 3,0 & 18,5 & 148 \\
\hline 15 & 11,4 & 4,8 & 5,8 & 1,2 & 72,3 & 2,0 & 0 & 0,5 & 1,248 & 1,240 & 0,4 & 41,0 & 138 \\
\hline 16 & 4,0 & 1,5 & 2,2 & 2,2 & 27,0 & 2,5 & - & 0,3 & 0,447 & 0,513 & 3,6 & 12,5 & 52 \\
\hline
\end{tabular}

Nota-se uma acentuada modificação na evolução do sódio com um predomínio do cálcio.

Praticamente, o único ânion presente é o $\mathrm{HCO}_{3}^{-}$. Apresenta uma variação de 12 a $100 \mathrm{ppm}$, e como para o cálcio, apresenta um valor de 4 a 5 vezes maior para oeste que para o aquíffero em Ribeirão Preto.

Quanto à sílica, somente um poço (n. 2, no arenito Botucatu) apresenta valor extremamente baixo $(8,5$ ppm) e está situado dentro da faixa de solubilidade do quartzo à temperatura de $25^{\circ} \mathrm{C}$ (Kramer, 1968). As águas que percolam o basalto apresentam valores maiores $(30,5$ e $29,5 \mathrm{ppm})$.

As variações de $\mathrm{pH}, \mathrm{HCO}_{3}^{-}$e $\mathrm{Ca}^{2+}$ entre as amostras, permitem uma ariálise do comportamento dessas águas em vista do equilibrio químico dos carbonatos, cujos aspectos cinéticos e termodinâmicos foram estudados por Roques $(1961,1962,1964)$ e Caro (1965). Os valores de $\mathrm{CO}_{2}$ livre, $\mathrm{P}_{\mathrm{CO}}, \mathrm{pH}$ equilíbrio para as 16 amostras foram calculadas e apresentadas na Tab. 4. Na ausência de fonte de $\mathrm{CO}_{2}$, no aquífero $\left(\mathrm{CO}_{2}\right.$ vulcânico, oxidação de matéria orgânica) os valores observados são praticamente devidos ao ar existente no solo. A pressão parcial do $\mathrm{CO}_{2}$ é da ordem de 2 a $3 \cdot 10^{-2}$ atmosfera e que representam de 50 a 100 vezes o teor atmosférico $\left(\mathrm{CO}_{2} \cong 320 \mathrm{ppm}\right)$. A Fig. 5 apresenta os valores entre $\mathrm{pH}$ real das águas e o $\mathrm{pH}$ de equilibrio, no qual se verifica uma "agressividade" da água para leste $(2,3,4,5)$ e águas próximas ao equilíbrio para oeste (poços 13 e 14). 
Tabela 4 - Parâmetros determinados para o equilibrio dos carbonatos

\begin{tabular}{rrrr}
\hline $\mathrm{N}^{\mathrm{o}}$ & $\begin{array}{c}\mathrm{CO}_{2} \text { livre } \\
\mathrm{ppm}\end{array}$ & $\begin{array}{c}\mathrm{PCO}_{2} \\
\left(10^{-2} \text { atm }\right)\end{array}$ & $\begin{array}{c}\mathrm{pH} \\
\text { equilibrio }\end{array}$ \\
\hline 1 & 36,8 & 2,5 & 9,15 \\
2 & 3,1 & 0,2 & 10,06 \\
3 & 50,0 & 3,3 & 10,25 \\
4 & 39,0 & 2,7 & 9,76 \\
5 & 21,3 & 1,4 & 9,73 \\
6 & 28,2 & 1,9 & 9,47 \\
7 & 33,7 & 2,3 & 9,09 \\
8 & 38,0 & 2,6 & 9,22 \\
9 & 39,1 & 2,6 & 9,27 \\
10 & 42,2 & 2,8 & 8,92 \\
11 & 45,7 & 3,2 & 8,72 \\
12 & 39,4 & 2,7 & 8,22 \\
13 & 3,0 & 0,2 & 8,09 \\
14 & 1,0 & 0,08 & 8,08 \\
15 & 45,8 & 2,8 & 8,60 \\
16 & 1,0 & 0,07 & 9,40 \\
\hline
\end{tabular}

O estudo petrográfico dos basaltos mostram que são compostos praticamente por $50 \%$ de minerais, que apresentam facilidade à alteração (plagioclásios e piroxênios). Os produtos de alteração de minerais primários, em sua quase totalidade, pertencem ao grupo das argilas; são bastante variáveis e têm sido objetivo de numerosos estudos (Millot, 1964 e Sieffermann, 1971). As sequêencias dos minerais de neoformação podem ser assim esquematizadas (Tardy, 1969) no sentido de alteração e lixiviação crescente.

- Feldspatos - leucita, vermiculita, montmorilonita, montmorilonita-Al, caolinita, gibsita.

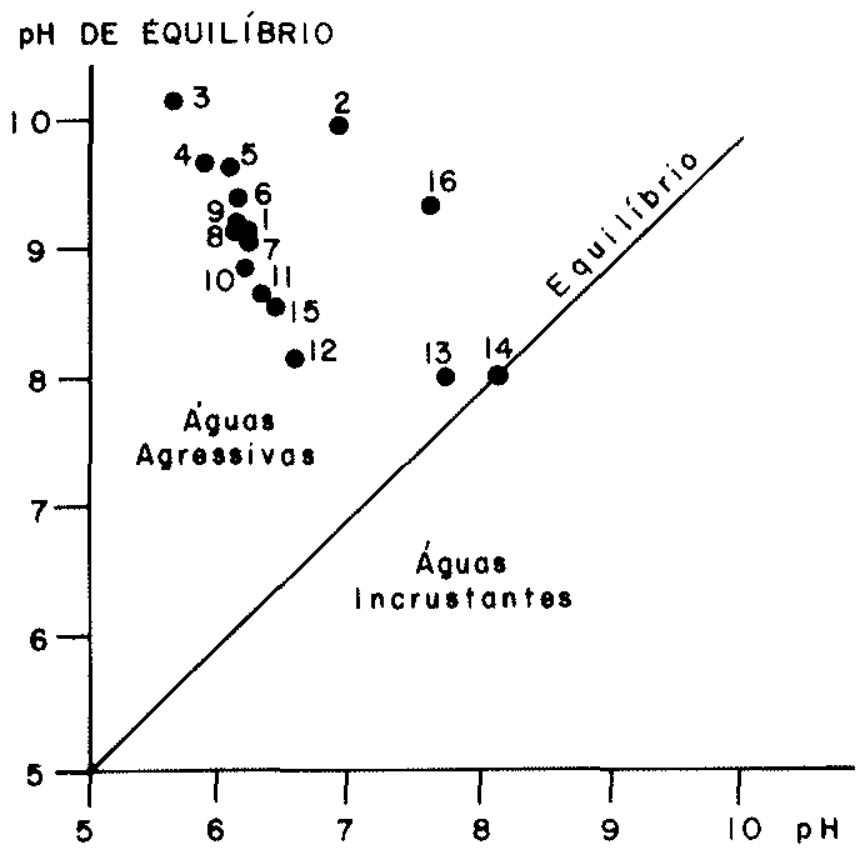

Figura 5 - Relação entre o pH das águas e o pH de equilíbrio
- Biotitas - clorita, vermiculita, montmorilonita, montmorilonita-Al, caolinita, gibsita (?), goetita.

- Anfibólios e Piroxênios - clorita, vermiculita, montmorilonita, caolinita, goetita.

- Muscovitas - vermiculita, montmorilonita, caolinita (?)

Verifica-se por essa sequiência que a evolução dos minerais secundários se processa em termos de empobrecimento dos cátions alcalinos e mesmo de sílica.

Assim sendo, é possivel estudar as rochas, solos, águas de percolação e águas subterrâneas em termos de equilíbrio, de cinética e de balanceamento químico. No caso, o número reduzido de dados e a ausência, em particular, da análise de água de percolação (exclusão feita à fonte analisada) e de análises químicas e mineralógicas completas das diferentes frações e horizontes dos solos a diferentes estágios de evolução, não permite um maior aprofundamento do estudo, mas será possível comparar globalmente a composição da água do aquífero com a composição dos basaltos e a dos minerais secundários de alteração.

Com efeito, a Formação Botucatu, constituida predominantemente de grãos de quartzo, praticamente não intervém na composição química do aquífero.

Por sua vez, o caráter químico da água é função da percolação da água, nos solos formados dos produtos de alteração dos basaltos.

Equilíbrio da água e dos minerais de alteração dos plagioclásios Os termos extremos da série dos feldspatos plagioclásios são a albita $\left(\mathrm{Na}^{-} \mathrm{AlSi}_{3} \mathrm{O}_{8}\right)$ e a anortita $\left(\mathrm{CaAl}_{2} \mathrm{Si}_{2} \mathrm{O}_{8}\right)$. Dois são os sistemas termodinâmicos que podem ser considerados:

$\mathrm{Na}_{2} \mathrm{O}-\mathrm{Al}_{2} \mathrm{O}_{3}-\mathrm{SiO}_{2}-\mathrm{H}_{2} \mathrm{O}$ e $\mathrm{CaO}-\mathrm{Al}_{2} \mathrm{O}_{3}-\mathrm{SiO}_{2}-\mathrm{H}_{2} \mathrm{O}$, entre os dois plagioclásios e seus minerais de alteração (montmorilonita, caolinita, gibsita). 
Os estudos termodinâmicos das diferentes reações possiveis, as determinações das constantes de equilíbrio e sua utilização em geoquímica, foram objetos de numerosas publicações: Feth et al.(1964), Harris e Adams (1966), Garrels (1967 e 1975), Garrels e Mackenzie (1967), Bricker e Garrels (1967), Kramer (1968), Tardy (1969), Paces (1972 e 1973), Tardy e Garrels (1974).

Para os dois sistemas considerados, todas as reações possiveis mostram que os equilibrios entre as diferentes fases minerais podem ser estabelecidos dois a dois, em termos de:

$\log \left(\mathrm{H}_{4} \mathrm{SiO}_{4}\right), \log \left(\mathrm{Na}^{+}\right) /_{\left(\mathrm{H}^{+}\right)}$e de $\log \left(\mathrm{Ca}^{2+}\right) /_{\left(\mathrm{H}^{+}\right)^{2}}$ Nessas condições, é possível estabelecer os dois diagramas das Figs. 6 e 7 que mostram os domínios de equilibrio dos dois plagioclásios e de seus minerais de alteração.

Para o estabelecimento desses diagramas, os valores numéricos das constantes de equilíbrio foram os calculados a $25^{\circ} \mathrm{C}$ por Tardy (1969) a partir de valores de energia livre padrão de formação de minerais publicados por Kramer (1968). Os valores numéricos das energias livres de formação dos minerais nâo são conhecidos com grande precisão. Particularmente, no caso das montmorilonitas na qual a substituiçăo dos cátions por

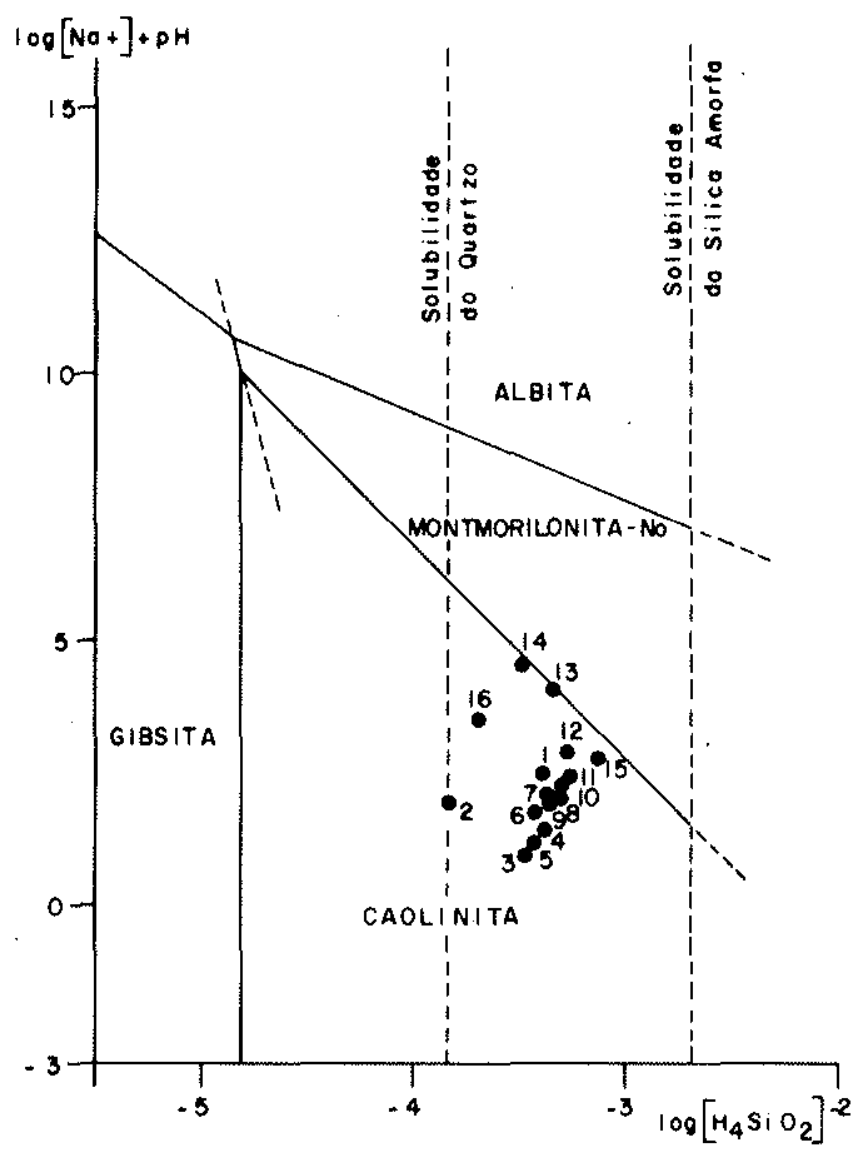

Figura 6 - Diagrama de equilíbrio albita - montmorilonita - caolinita - gibsita $\left(25^{\circ} \mathrm{C}\right.$ e $\left.1 \mathrm{~atm}\right)$ outros cátions na estrutura mineral é possivel em quase todas as proporções e não existe uma fórmula estequio. métrica bem definida. Como conseqüência, neste trabatho foram utilizados os dois extremos:

Montmorilonita - $\mathrm{Na}, \mathrm{NaAl}_{7} \mathrm{Si}_{41} \mathrm{O}_{30}(\mathrm{OH})_{0}$

Montmorilonita - $\mathrm{Ca}, \mathrm{CaAl}_{14} \mathrm{Si}_{22} \mathrm{O}_{60}(\mathrm{OH})_{12}$

dos quais as energias livres de formação são dadas por Kramer (op. cit.). Para o quartzo e a sílica amorfa, utilizou-se a média dos valores dos produtos de solubilidade publicados por Kramer (op. cit.) e Truessell e Jones (1974).

Os dois diagramas mostram que a transformação da caolinita em gibsita é independente do teor em cátions e do $\mathrm{pH}$; que a alteração da anortita em caolinita é independente do teor em sílica mas que a montmorilonita cálcica é uma fase mineral mais rica em sílica que à anortita.

Os pontos representativos das diferentes amostras plotadas sobre os dois diagramas mostram que as águas estão todas dentro do domínio de equilibrio da caolinita. De outro lado, verifica-se que as águas apresentam uma tendência de se aproximarem no domínio da montmorilonita, principalmente as águas mais mineralizadas (poços 13 e 14) situados a oeste (aquífero confinado). Esses resultados estão de acordo com as observações

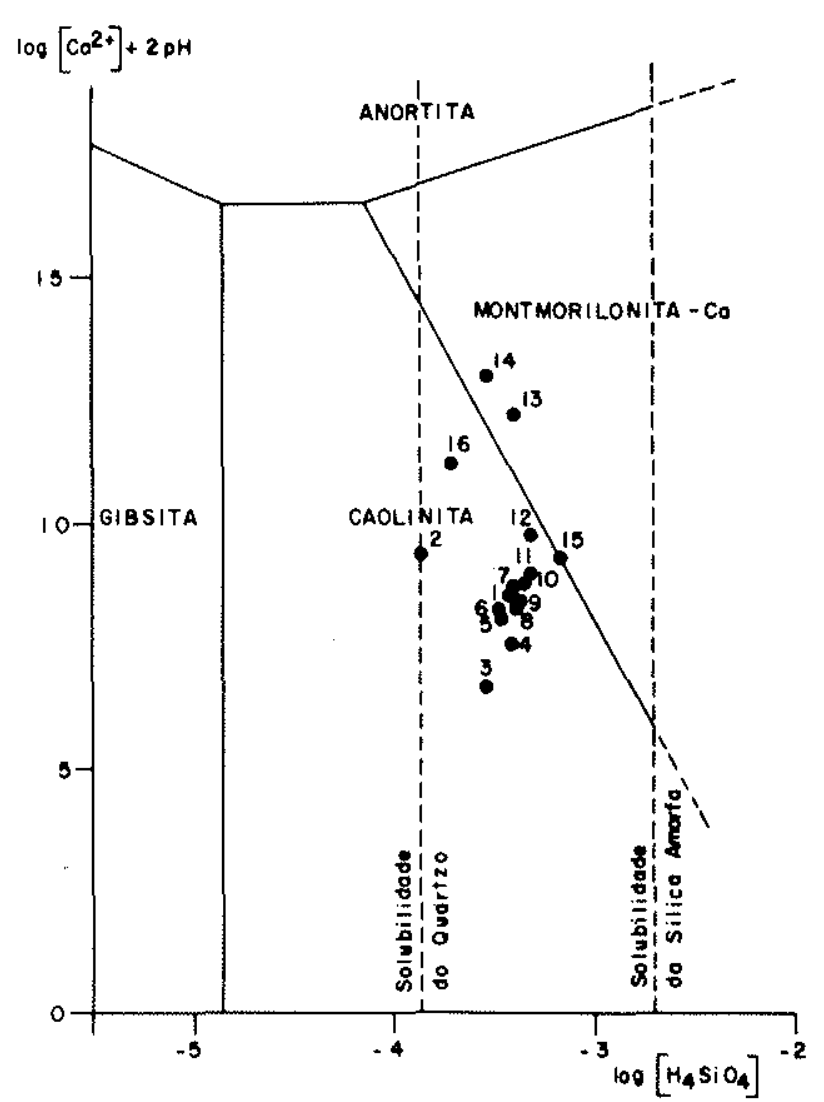

Figura 7 - Diagrama de equilíbrio anortita - montmorilonita - caolinita - gibsita $\left(25^{\circ} \mathrm{C}\right.$ e 1 atm $)$ 
efetuadas por Tardy (1968): no qual a montmorilonita se forma em águas quimicamente confinadas, por outro lado, esta formação de montmorilonita explicaria a diminuição do teor em sílica (poço n. 14 ).

Mobilidade Geoquímica dos elementos Comparando-se a composição química da água, da rocha primária e de seus produtos de alteração, é possivel determinar as velocidades relativas através das quais os elementos que estão na fase sólida podem passar em solução nas águas. Para isso, foi adotado o método proposto por Tardy (1969), que permite uma comparação mais elaborada que o método de Anderson e Hawkes (1968).

Seja $E_{\mathrm{c}}$ o teor em $\mathrm{mg} / 1$ do elemento $E$ na água; $E_{\mathrm{r}} \circ$ teor em $\mathrm{g}$ do elemento $E \mathrm{em} 100 \mathrm{~g}$ de rocha, $R_{\mathrm{e}}$ e $R_{\mathrm{r}}$ os teores, expressos nas mesmas unidades precedentes, do elemento de referência na água e na rocha. A mobilidade do elemento $E$ é expresso por:

$$
M_{\mathrm{E}}=\frac{E_{\mathrm{e}} / E_{\mathrm{r}}}{R_{\mathrm{e}} / R_{\mathrm{r}}} \cdot 10^{3}
$$

O elemento tomado como referência é o sódio, que é dos íons mais móveis e que é pouco retido nos solos. A Tab. 5 apresenta os valores obtidos de mobilidade para os diferentes grupos de amostras. A ordem de mobilidade verificada é:

$$
\mathrm{K}>\mathrm{Ca}>\mathrm{Na}>\mathrm{Mg}>\mathrm{Si}>\mathrm{Ti}>\mathrm{Fe}>\mathrm{Al}
$$

os teores de $\mathrm{K}^{+}$. superiores ao $\mathrm{Na}^{+}$nas águas da região foram verificados em estudos procedentes, realizados por Sinelli (1970 e 1971a). Por outro lado, em trabalho experimental com diabásios da região em laboratório, Raphael (1972) igualmente observou este comportamento, que parece ser comum na região.

ESTUDOS ISOTÓPICOS O estudo hidrogeológico e geoquímico das águas subterrâneas de Ribeirão Preto permitiram a avaliação de um conjunto de fatos concernentes à alimentação e ao comportamento do aquífero. O estudo isotópico (carbono 14, carbono 13, trítio, oxigênio-18 e deutério) permitiu précisar a evolução do aquífero e de aprofundar as conclusões hidrogeológicas e geoquímicas.

A metodologia experimental, bem como a utiliza. ção isotópica ambiental em hidrologia foram obtidas de: A.I.E.A. (1968, 1970 e 1974); UNESCO (1973); DROST et al. (1973); Libby (1955 e 1967); Olson et al. (1963); Rafter (1961); Leger (1963); Michael et al.
(1972); Damon et al. (1972); Nydal (1968); Munnich et al. (1967); Duch (1968); Noakes et al. (1965); Cameron (1967); Olive (1970); Hubert (1971); Roether (1967); A.I.E.A. (1969, 70, 71, 73, 75); Gonfiantini (1973); Graig (1961b); Boato (1960); Gat e Dansgaard (1972); Gar (1971)

Amostragem Carbono 14 e Carbono $13 \quad \mathrm{O}$ método utilizado para a amostragem foi (Davis et al:, 1968 e Florkwski et al., 1969), da precipitação de $\mathrm{BaCO}_{3}$ por adição de $\mathrm{BaCl}_{2}$ em meio alcalino. Esse método é muito bom, e apresenta a vantagem de ser bastante rápido sem necessitar de equipamentos complexos.

Trítio e isótopos estáveis Para a medida do teor em trítio, e da composição de $\mathrm{O}^{18}$ e deutério na água, foram usados 0,5 litros (enriquecidos eletroliticamente) e $20 \mathrm{ml}$ respectivamente de água amostrada. A única observação é que os frascos foram hermeticamente fechados, a fim de evitar contaminação com trítio atmosférico e de fracionamento isotópico para os isótopos estáveis.

Resultados analiticos As medidas das atividades do ${ }^{14} \mathrm{C}$, os valores de $d^{13} \mathrm{C}$, os teores em trítio e a composição em isótopos estáveis (oxigênio-18 e deutério) estão apresentados na Tab. 6.

Interpretação Para as águas do aquífero, as atividades do ${ }^{14} \mathrm{C}$ se apresentam em 3 grupos: próximos a $100 \%$ para os poços $2,4,5$ e 10 ; entre 65 e $74 \%$ para os poços $1,7,8,11$ e 12 e inferiores a 20 e $10 \%$ para os poços $13 \mathrm{e}$ 14.

A semelhança entre a amostra do poço 1 (Arenito Botucatu) e os poços 7, 8, 11 e 12 (Basalto + Botucatu) em Ribeirão Preto, vem de encontro ao que foi interpretado na parte hidroquímica (região de recarga e aquífero não confinado). A atividade do ${ }^{14} \mathrm{C}$, relativamente alta do poço n: 2 , não é significativa e se deve a problema de bombeamento (ar comprimido). De forma geral, a atividade do ${ }^{14} \mathrm{C}$ diminui de leste para oeste. A Fig. 8 mostra esse comportamento.

Com exceção do poço $\mathrm{n}^{\circ}$. 10 , as águas subterrâneas apresentam baixos teores de trítio, praticamente iguais a zero (exceção feita aos poços 2 (Lagoinha) e 10 (Pompolo) ).

Para as águas subterrâneas do hemisfério norte, a seguinte regra geral é ađmitida (A.I.E.A., 1968):

- Águas subterrâneas, com teores de trítio inferiores a 5 U.T., indicam águas não contaminadas pelo trí-

\begin{tabular}{|c|c|c|c|c|c|c|c|c|}
\hline Amostras & $\mathrm{Si}$ & $\mathbf{A l}$ & $\mathrm{Ti}$ & $\mathrm{Fe}$ & $\mathbf{M g}$ & $\mathrm{Ca}$ & $\begin{array}{c}\mathrm{Na} \\
\text { (ref.) }\end{array}$ & $\mathbf{K}$ \\
\hline 3 a 10 & 680 & 7 & 300 & 50 & 700 & 1000 & 1000 & 4640 \\
\hline 11 e 12 & 290 & 2 & 100 & 20 & 690 & 1040 & 1000 & 2320 \\
\hline 13 e 14 & 150 & 2 & 75 & 12 & 210 & 1230 & 1000 & 1290 \\
\hline 1 a 14 & 360 & 4 & 170 & 30 & 500 & 1020 & 1000 & 2780 \\
\hline
\end{tabular}

Tabela 5 - Mobilidade relativa dos elementos 
Tabela $6-$ Resultados isotópicos

\begin{tabular}{rcccccc}
\hline No & ${ }^{14} \mathrm{C}_{\mathrm{NBS}} \%$ & $\delta^{13} \mathrm{C}_{\mathrm{PDB}} \%$ & ${ }^{3} \mathrm{H}_{\mathrm{U} . \mathrm{T} .}$ & $\begin{array}{c}\text { Data de } \\
\left({ }^{*} \mathrm{O} \text { e } \mathrm{D}\right)\end{array}$ & $\delta_{18} \mathrm{O}_{\mathrm{SMOW}} \%$ & $\delta_{\mathrm{D}} \mathrm{SMOW}^{\%}$ \\
\hline 1 & $75,3 \pm 1,4$ & $-17,06$ & $1,0 \pm 0,5$ & 4.74 & $-6,70$ & $-45,3$ \\
2 & $103,8 \pm 5,0$ & $-17,78$ & $5,7 \pm 0,5$ & 4.74 & $-7,11$ & $-45,7$ \\
3 & - & - & $2,9 \pm 0,4$ & 4.74 & $-7,13$ & $-46,8$ \\
4 & $93,2 \pm 1,5$ & $-19,14$ & $1,0 \pm 0,4$ & 4.74 & $-7,14$ & $-46,0$ \\
5 & $98,7 \pm 1,6$ & $-19,80$ & $2,1 \pm 0,3$ & 4.74 & $-7,11$ & $-45,3$ \\
6 & - & - & $<1$ & 4.74 & $-6,86$ & $-44,9$ \\
7 & $74,0 \pm 1,4$ & $-18,46$ & $4,9 \pm 0,5$ & 4.74 & $-6,82$ & $-44,4$ \\
8 & $66,8 \pm 1,2$ & $-18,28$ & $2,2 \pm 0,4$ & 4.74 & $-7,20$ & $-44,4$ \\
9 & - & - & $3,3 \pm 0,4$ & 4.74 & $-6,95$ & $-46,1$ \\
10 & $93,6 \pm 1,3$ & $-18,36$ & $14,4 \pm 0,7$ & 4,74 & $-6,62$ & $-44,5$ \\
11 & $65,3 \pm 1,2$ & $-18,75$ & $2,3 \pm 0,4$ & 4.74 & $-6,87$ & $-44,2$ \\
12 & $66,7 \pm 1,2$ & $-18,28$ & $2,0 \pm 0,4$ & 4.74 & $-7,14$ & $-44,4$ \\
13 & $17,5 \pm 1,1$ & $-9,89$ & $1,1 \pm 0,4$ & 4.74 & $-8,76$ & $-62,4$ \\
14 & $6,3 \pm 1,1$ & $-7,66$ & $1,4 \pm 0,5$ & 4.74 & $-9,37$ & $-66,0$ \\
15 & $96,2 \pm 1,3$ & $-13,31$ & $26,0 \pm 1$ & - & - & - \\
16 & $135,2 \pm 7,6$ & $-8,18$ & $17,0 \pm 0,8$ & 4.74 & $-8,04$ & $-51,8$ \\
\hline
\end{tabular}

Obs.: Todas as amostras foram coletadas em abril e maio de 1973.

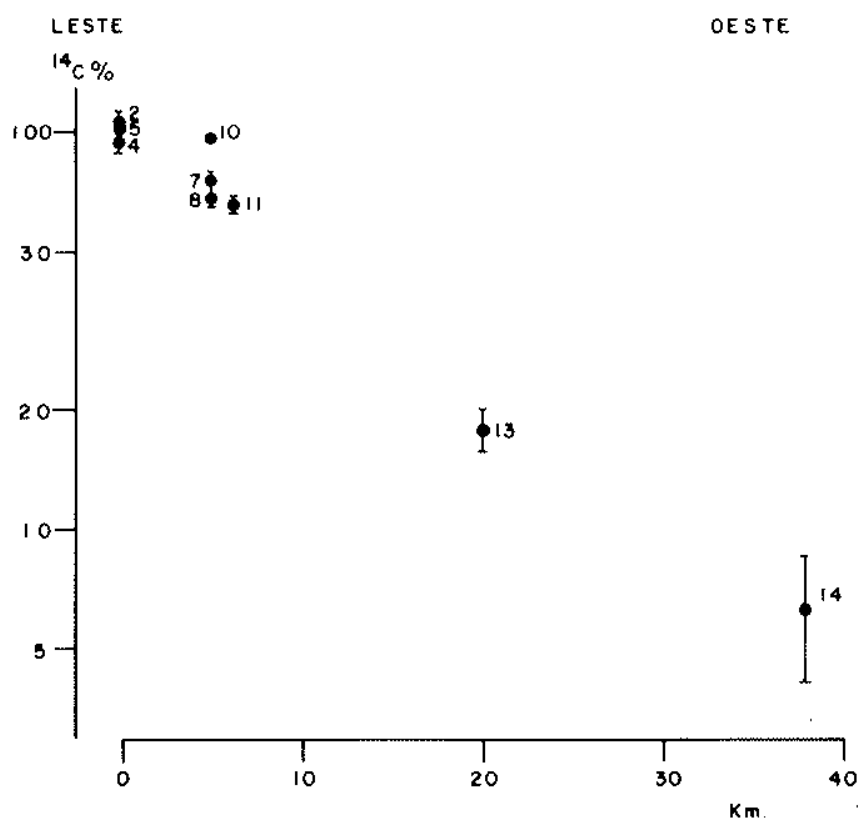

Figura 8 - Atividades ${ }^{14} \mathrm{C}( \pm 2 o)$ em função da distância dos poços

tio artificial de origem termonuclear num periodo nunca inferior a 20-25 anos. Essa idade mínima corresponde praticamente a 2 períodos de trítio devidos às precipita. ções pluviométricas anteriores a 1953 a niveis de 8 a 10 U.T.

-Águas com teores entre 5 a 20 U.T., correspondendo a águas dentro da média de 20 a 25 anos, porém não contaminadas por trítio artificial, são águas misturadas com águas recentes contaminadas.

- Com teores superiores a 20 U.T., representando águas de precipitações recentes contaminadas por trítio artificial.

Para o hemisfério sul, os niveis de trítio encontrados nos últimos 20 anos foram inferiores aos valores en- contrados no hemisfério norte. Nessas condições, para a região de Ribeirão Preto, os baixos teores em trítio indicam que a infiltração (recarga), mesmo a que se processa através dos basaltos altamente físsurados, não é um processo tão rápido. O poço n: 10 , por outro lado, dá indicações que fogem à țendência geral, mostrando uma zona de recarga altamente privilegiada.

Os valores de $\delta^{13} \mathrm{C}$ são bastante homogêneos para os poços situados em região de Ribeirão Preto, tendo como valor médio

$$
\delta^{13} \mathrm{C}=-18 \cdot 4 \pm 0,8
$$

Esse alto valor negativo para as águas subterrâneas, está de acordo com os resultados do estudo geoquímico que mostram ser estas águas ricas em $\mathrm{CO}_{2}$ livre e que os bicarbonatos em solução provêm, essencialmente, da hidratação de $\mathrm{CO}_{2}$ dissociado, porque a composição química da água é principalmente devida à hidrólise ácida dos minerais de basalto e de seus produtos de alteração, por reaçðes do tipo:

$$
\begin{array}{cc}
\mathrm{CaAl}_{2} \mathrm{Si}_{2} \mathrm{O}_{2}+3 \mathrm{H}_{2} \mathrm{O}+2 \mathrm{CO}_{2} & \mathrm{Al}_{2} \mathrm{Si}_{2} \mathrm{O}_{3}(\mathrm{OH})_{4}+\mathrm{Ca}^{2+}+\mathrm{HCO}_{3}^{-} \\
\text {anortita } & \text { caolinita }
\end{array}
$$

Nesse caso, o carbono dos bicarbonatos provém, na totalidade, do $\mathrm{CO}_{2}$ contido na zona de aeração do solo. Aplicando-se as equaçðes clássicas de correção das atividades:

$$
\begin{aligned}
Q_{\mathrm{q}} & =\frac{m_{\mathrm{CO}_{2}}+1 / 2 m_{\mathrm{HCO}_{3}^{-}}}{m_{\mathrm{CO}_{z}}+m_{\mathrm{HCO}}} \\
Q_{\mathrm{q}} & =\text { fator de correção química } \\
Q_{1} & =\frac{\delta^{13} C_{\mathrm{tot}}-\delta^{13} C_{\text {catc. }}}{\delta^{13} C_{\text {a.s }}-\delta^{13} C_{\text {calc. }}} \\
\left(Q_{1}\right. & =\text { fator de cơreção isotópica })
\end{aligned}
$$


Tabela 7 - Atividades corrigidas das águas de Ribeirão Preto

\begin{tabular}{rcccc}
\hline N. & $\begin{array}{c}\mathrm{Q}_{\mathrm{I}} \\
(\text { a.s. }=25 \%)\end{array}$ & $\mathrm{Q}_{\mathrm{c}}$ & ${ }^{\star 4} \mathrm{C} / \mathrm{Q}_{1} \%$ & ${ }^{44} \mathrm{C} / \mathrm{Q}_{\mathrm{c}} \%$ \\
\hline 1 & 0,68 & 0,79 & $110,3 \pm 2,0$ & $95,4 \pm 1,8$ \\
2 & 0,71 & 0,63 & $146 \pm 7$ & $165 \pm 8$ \\
3 & - & 0,92 & - & - \\
4 & 0,76 & 0,88 & $121,8 \pm 1,8$ & $106,2 \pm 1,6$ \\
5 & 0,79 & 0,83 & $124,7 \pm 2,0$ & $118,7 \pm 1,9$ \\
6 & - & 0,82 & - & - \\
7 & 0,74 & 0,79 & $100,0 \pm 2,0$ & $94,0 \pm 1,8$ \\
8 & 0,73 & 0,81 & $91,4 \pm 1,6$ & $81,9 \pm 1,4$ \\
9 & - & 0,82 & - & - \\
10 & 0,74 & 0,80 & $127,5 \pm 1,8$ & $116,6 \pm 1,6$ \\
11 & 0,75 & 0,76 & $87,1 \pm 1,5$ & $86,3 \pm 1,5$ \\
12 & 0,73 & 0,69 & $91,3 \pm 1,7$ & $97,3 \pm 1,8$ \\
13 & 0,40 & 0,52 & $44,3 \pm 2,7$ & $33,7 \pm 2,0$ \\
14 & 0,31 & 0,51 & $20,7 \pm 3,5$ & $12,5 \pm 2,1$ \\
15 & 0,53 & 0,73 & $180,9 \pm 2,5$ & $131,2 \pm 1,8$ \\
16 & - & - & - & - \\
\hline
\end{tabular}

Obtivemos, assim, as atividades corrigidas (Tab 7). No caso $Q_{1}$, o valor de $d^{13} \mathrm{C}$ inicial para o ar contido nos solos foi escolhido como $-25 \%$ (Pearson, 1966; Pearson e White, 1967); este é um valor médio para o ciclo de fotossintese de Calvin (valor médio para - 18,4\% para águas em clima tropical, Fig. 9). Para a maior parte das amostras, obtivemos uma atividade corrigida superior a $100 \%$, o que indicaria a presença de carbono 14 de origem artificial, posterior a 1953. Indicação contrária é dada pelos teores em trítio, que mostram serem es. sas águas não contaminadas por radioisótopos artificiais de origem termonuclear.

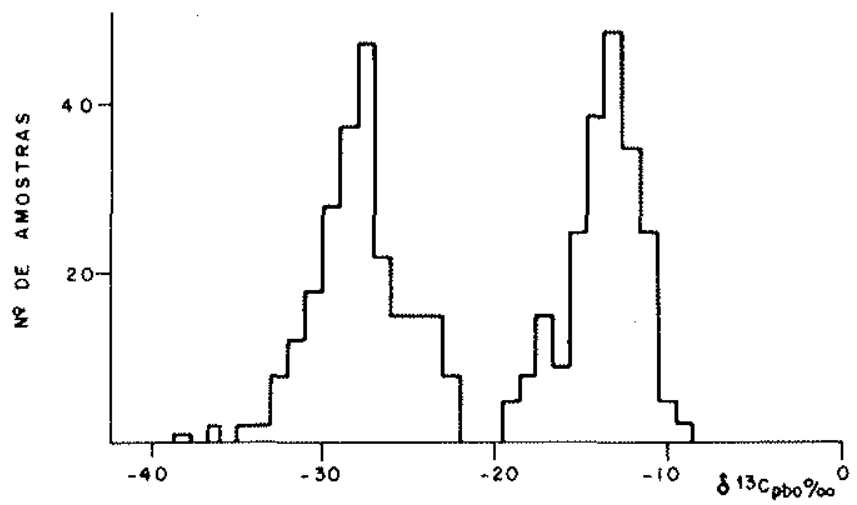

Figura 9 - Composição isotópica do carbono de plantas terrestres superiores (após J.C. Lerman, 1972)
Vimos pelo estudo geoquímico efetuado que as caracteristicas químicas das águas são essencialmente obtidas pela alteração dos plagioclásios e que não há introdução de carbono inativo em solução. Como conseqüência, as atividades de ${ }^{14} \mathrm{C}$ não devem ser corrigidas, o que é corroborado pelos teores de trítio.

O grupo de poços onde a atividade não corrigida de ${ }^{14} \mathrm{C}$ está compreendida entre valores de 65 e $75 \%$, tendo valores elevados de bicarbonatos, conservam o mesmo $\delta^{13} \mathrm{C}$ que as águas pouco mineralizadas, onde a atividade é próxima de $100 \%$.

Essa observação confirma que o crescimento do teor em bicarbonato não é devido à dissolução de calcita, mineral ausente no aquífero (exceto em pequenas quantidades em cavidades nos basaltos ou de origem secundária). Nesse caso, o carbono 13 aparece, portanto, como indicador químico de opção para determinar a origem das espécies carbonatadas dissolvidas.

Com efeito, comparando-se as reações de alteração da anortita e de dissolução de calcita, verifica-se que, do ponto de vista estequiométrico, não é possivel diferenciar as duas reaçðes pelas razōes iônicas de $\mathrm{Ca}^{+2} \mathrm{e}$ $\mathrm{HCO}_{3}^{-}$.

Entretanto, quando o aquífero evolui para sistema fechado (confinado), é possível diferenciar as duas reações pelo balanço químico do carbono em solução, pois a quantidade de carbono em solução é constante quando provém da alteração da anortita, e esta quantidade aumenta quando provém da dissolução da calcita. $O$ ba* lanço químico do carbono foi calculado para todos os poços (Tab. 8). As diferenças importantes de um poço a outro na região de Ribeirão Preto confirmam que o aquîfero apresenta característica de não confinamento. Em particular, os poços 11 e 12 possuem teores em carbono mais elevados. 
Tabela 8 - Balanço do carbono

\begin{tabular}{cccccccc}
\hline No & $\begin{array}{c}\mathrm{C} \\
\mathrm{de} \mathrm{CO}_{2} \\
(\mathrm{mg} / \mathrm{l})\end{array}$ & $\begin{array}{c}\mathrm{C} \\
\mathrm{de} \mathrm{HCO}_{3}^{-} \\
(\mathrm{mg} / \mathrm{l})\end{array}$ & $\begin{array}{c}\mathrm{C} \\
\mathrm{Total} \\
(\mathrm{mg} / \mathrm{l})\end{array}$ & $\mathrm{N}$. & $\begin{array}{c}\mathrm{C} \\
\mathrm{de} \mathrm{CO}_{2} \\
(\mathrm{mg} / \mathrm{l})\end{array}$ & $\begin{array}{c}\mathrm{C} \\
\mathrm{de} \mathrm{HCO}_{3} \\
(\mathrm{mg} / \mathrm{l})\end{array}$ & $\begin{array}{c}\mathrm{C} \\
\mathrm{Total} \\
(\mathrm{mg} / \mathrm{l})\end{array}$ \\
\hline 1 & 10,0 & 7,4 & 17,4 & 9 & 10,7 & 6,2 & 16,9 \\
2 & 0,8 & 2,7 & 3,5 & 10 & 11,5 & 7,5 & 19,0 \\
3 & 13,6 & 2,5 & 16,1 & 11 & 12,5 & 11,7 & 24,2 \\
4 & 10,6 & 3,5 & 14,1 & 12 & 10,7 & 18,2 & 28,9 \\
5 & 5,8 & 3,0 & 8,8 & 13 & 0,8 & 19,5 & 20,3 \\
6 & 7,7 & 4,5 & 12,2 & 14 & 0,3 & 18,3 & 18,6 \\
7 & 9,2 & 6,8 & 16,0 & 15 & 12,5 & 14,2 & 26,7 \\
8 & 10,4 & 6,0 & 16,4 & 16 & 0,3 & 5,3 & 5,6 \\
\hline
\end{tabular}

Os dois poços situados a oeste (13 e 14), para os quais o estudo geoquímico caracteriza comportamento confinado, possuem um teor médio de carbono próximo à média das águas de Ribeirão Preto; o teor mais baixo do poço n. 14 em relação ao do n. 13 é devido à precipitação de $\mathrm{CaCO}_{3}$, porque atingiu a saturação. $\mathrm{O}$ teor relativamente constante, entre Ribeirão Preto e a parte oeste do aquiífero, está de acordo com as conclusōes do estudo geoquímico, que mostra uma mineralização mais acentuada nos poços 12 e 14, devida principalmente à alteração dos plagioclásios (tanto $0 \mathrm{Ca}^{+2}$ como $\mathrm{Na}^{+}$aumentam nas mesmas proporções).

Também os valores de $\delta^{13} \mathrm{C},-9,89 \mathrm{e}-7,66 \%$ para os poços 13 e 14 estão em contradição com a característica geoquímica do aqüífero. Tais valores de $\delta^{13} \mathrm{C}$ são habitualmente obtidos por dissolução de calcita, seja diretamente pela ação de $\mathrm{CO}_{2}$ livre, seja indiretamente pelo equilíbrio químico das águas quando se produz um fenômeno de troca iônica. Por outro lado, a hipótese de troca isotópica entre as espécies em solução e os carbonatos do aquífero deve ser excluída devido a ausência de carbonatos no aquífero. Como essas águas são de idade acentuada (atividade ${ }^{14} \mathrm{C}$ de 17,5 e $6,3 \%$ ), admite-se que a alimentação do aqüífero (recarga) se processou em clima diferente do atual, para o qual o ciclo de fotossintese das plantas estava dentro do ciclo de Hatsh-Slack, a menos que o ar atmosférico tivesse uma contribuição muito importante.

Tal contribuição do ar atmosférico é colocada em evidência nó caso da água do rio ( $\mathrm{N}$ : 16), para o qual o equilibrio isotópico com o ar atmosférico é igual a $-8,18 \%$ para o $8^{13} \mathrm{C}$ e a atividadè do ${ }^{14} \mathrm{C}$ igual a $135 \pm$ $\pm 8 \%$. A atividade de $\mathrm{CO}_{2}$ atmosférico, medido na mesma época, foi de $145 \pm 2 \%$. A água da fonte (N. 15) possui um $\delta^{13} \mathrm{C}$ de $13,31 \%$, realmente mais elevado que as águas subterrâneas. A rápida circulação da água nas físsuras do basalto fazem com que haja uma fase gasosa do ar atmosférico na água, o que explicaria o valor de $\delta^{13} \mathrm{C}$. Concluindo, verifica-se que realmente a composição química das águas é adquirida pela hidrólise dos feldspatos e seus produtos de alteração. $O$ carbono das espécies carbonatadas em solução provém exclusivamente do $\mathrm{CO}_{2}$, e as atividades ${ }^{14} \mathrm{C}$ representam as atividades reais da água.
Cálculo da velocidade aparente de circulação, permeabilidade e idade das águas Para o cálculo da velocidade aparente de circulação do aquífero, admite-se uma atividade de ${ }^{14} \mathrm{C}$ próxima de $70 \pm 5 \%($ poços $7,8,11)$ a oeste.

$$
\text { Pela relação } t=\frac{T}{L n_{2}}\left(\operatorname{Ln} \frac{A_{2}}{A_{1}}+\operatorname{Ln} \frac{Q_{1}}{Q_{2}}\right), \text { sendo } A_{1} \mathrm{e}
$$

$A_{2}$ as atividades medidas, $Q_{1}$ e $Q_{2}$ são os fatores de correção química ou isotópica. Usando a relação acima, sem correção para o carbono 13 , têm-se os seguintes tempos aparentes:

$$
\begin{aligned}
& \text { - entre Ribeirão Preto e Sertãozinho, } 11.000 \pm \\
& \pm 800 \text { anos } \\
& \text { - entre Sertãozinho e Barrinha, } 8.000 \pm 1.600
\end{aligned}
$$
anos.

Como as distâncias que separam Sertãozinho de Ribeirão Preto e Barrinha de Sertãozinho são respectivamente $15 \mathrm{~km}$ e $18 \mathrm{~km}$, a velocidade aparente de circulação no aquífero é: $\mathrm{m} / \mathrm{ano}$

- entre Ribeirão Preto e Sertãozinho $=1,4 \pm 0,1$ $\mathrm{m} /$ ano.

- entre Sertãozinho e Barrinha $=2,2 \pm 0,5$

Para estimar o valor da permeabilidade do aquífero foi utilizada a lei de Darcy para os arenitos (Castany, 1967):

$$
Q=K: i: S
$$

$Q=$ volume em $\mathrm{m}^{3} / \mathrm{h} ; i=$ gradiente hidráulico (adimensional), $S=$ área da seção transversal ao fluxo em $\mathrm{m}^{2}$, e $K=$ permeabilidade $\mathrm{em} \mathrm{m} / \mathrm{h}$.

A lei de Darcy pode ser também escrita sob a forma:

$$
Q=v: n: S(2)
$$

onde $n=$ porosidade efetiva do aqüífero e $\nu=$ velocidade aparente do fluxo através da seção S. Combinando-se (1) e (2) temos:

$$
K=\frac{\mathcal{V} \cdot n}{i} \quad \text { (Hanshaw et al., } 1965 \text { e 1974) }
$$

No caso das águas subterrâneas de Ribeirão Preto, o nível piezométrico médio é de $500 \mathrm{~m}$ na cidade de $\mathrm{Ri}$ beirão Preto, $495 \mathrm{~m}$ em Sertãozinho, distantes $15 \mathrm{~km}$. O 
gradiente hidráulico entre os dois pontos é da ordem de $0,33: 10^{-3}$. A porosidade média dos arenitos na região é de $15 \%$ (Sinelli, 1970). A velocidade média aparente de circulação do aquíífero entre os dois pontos é $1,4 \pm 0,1$ $\mathrm{m} /$ ano, o qué dá uma permeabilidade de

$$
K=7,10^{-2} \mathrm{~m} / \mathrm{h}
$$

Pode-se considerar que a "idade" das águas em Sertãozinho e Barrinha, avaliadas sem correção para o ${ }^{13} \mathrm{C}$, o valor superior sem correção e o valor inferior corrigindo a atividade com auxílio do $\delta^{13} \mathrm{C}$ :

\section{$6.500 \pm 500$ anos Sertãozinho \\ $14.000 \pm 500$ anos $13.000 \pm 1.500$ anos Barrinha $22.000 \pm 1.500$ anos}

Os valores de ${ }^{18} \mathrm{O}$ e deutério das amostras da região estão plotados na Fig. 10. O agrupamento (na região de Ribeirão Preto) mostra a identidade das águas, e permite concluir que a alimentação é devida exclusiva e diretamente de precipitações locais.

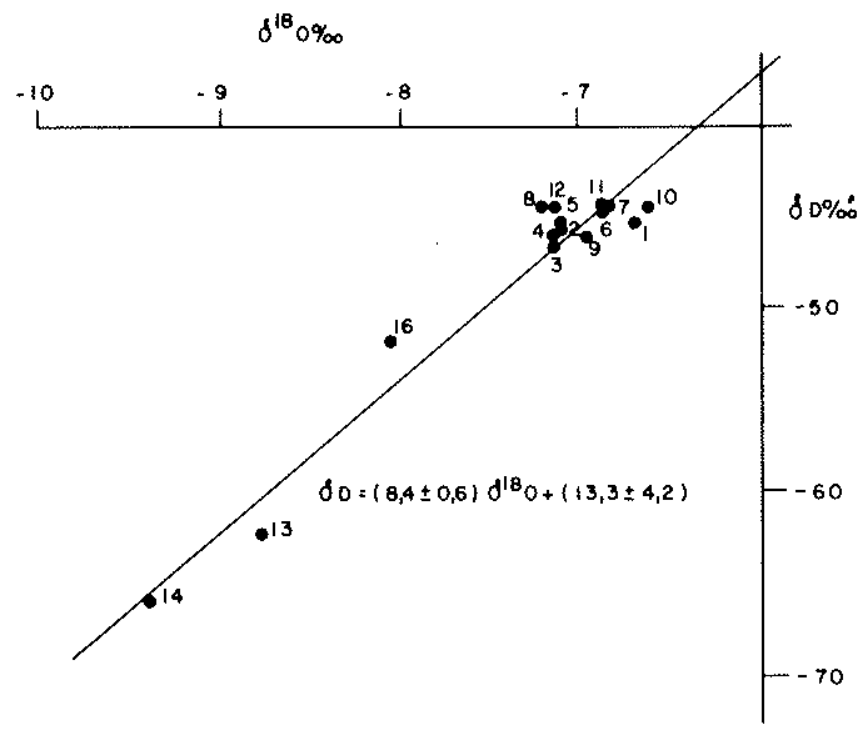

Figura 10 - Diagrama dos isótopos estáveis

Os valores mais negativos para os poços 13 e 14 confirmam os resultados do carbono 14. Com efeito, os isótopos estáveis mostram que a alimentação (recarga) do aquífero foi realizada em clima anterior ao Quaternário, mais frio que o atual, fase em que o ${ }^{14} \mathrm{C}$ situa-se próximo aos 10.000 anos. Os valores do carbono 13 correspondem a um ciclo de fotossintese do tipo Hatsh. -Slack (Fig. 9), atualmente observados em climas áridos e semi-áridos. Nessas condições, faz-se necessário admitir a existência, no passado, de um clima mais frio e mais árido que o atual. Um clima desse tipo existe atual. mente no norte do Chile.

CONCLUSÕES O estudo hidroquímico e isotópico, efetuado na região de Ribeirão Preto, confirmou da- dos hidrogeológicos bem como caracteriza aspectos relativos à recarga e evolução do aqüífero.

Do ponto de vista geoquímico, as principais verificações foram:

- as águas dos poços, perfurados unicamente no arenito, apresentam baixa mineralização e o teor de sílica corresponde praticamente à solubilidade do quartzo e representa a média da mineralização total.

- a mineralização aumenta para as águas de poços perfurados em basalto e arenito e, principalmente, nos perfurados só no basalto.

- a mineralização é adquirida pela hidrólise ácida dos minerais de basalto e seus produtos de alteração, e que constituem os solos da região.

- na cidade de Ribeirão Preto, o aquiifero apresenta um comportamento não confinado, e as características químicas são provenientes da zona nâo saturada do aquífero.

- os isótopos estáveis, oxigênio-18 e deutério apresentam homogeneidade de valores para o aquífero na cidade de Ribeirão Preto, indicando uma recarga unicamente devida às precipitações locais.

- os isótopos radioativos trítio e carbono 14 mostram que as águas de Ribeirão Preto são recentes e que não contêm trítio artificial.

- para a região oeste do aquiifero, os isótopos estáveis indicam que sua recarga foi efetuada por precipitações em clima mais frio que o atual.

- a Fig. 11 ilustra a evolução química do aquífero.

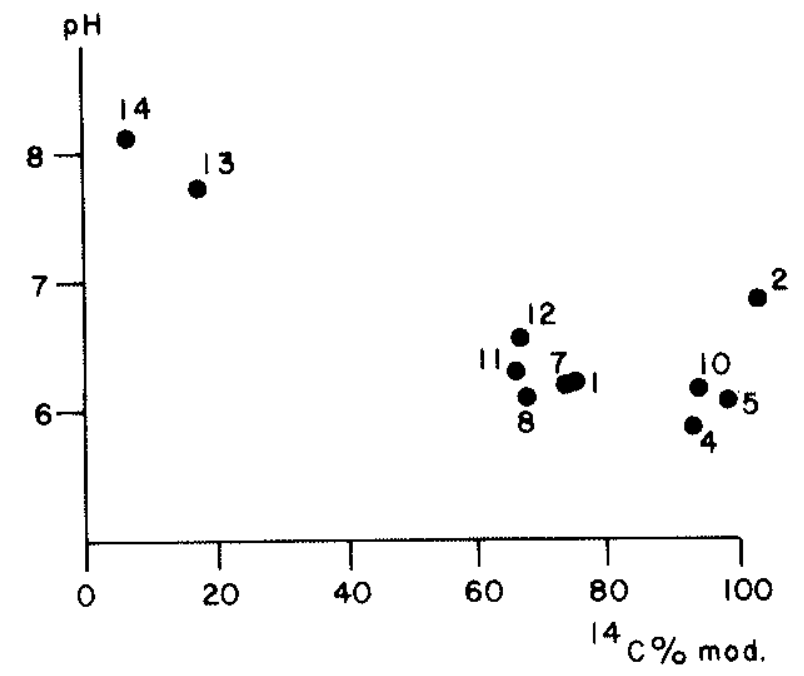

Figura 11 - Evolução química e isotópica do aquífero.

Agradecimentos As análises isotópicas, realizadas durante a execução deste trabalho, foram efetuadas no Centro de Geocronologia do 1.G.U.S.P. (carbono 14); C.E.N.A. de Piracicaba, SP (carbono 13); I.P.R. de Belo Horizonte (tritio) e l.A.E.A. de Viena (oxigênio-18 e deutério); aos quais expressamos nossos agradecimen. tos. 


\section{BIBLIOGRAFIA}

A.1.E.A. - 1968 - Guidebook on nuclear Teclrniques in Hydrology. Technical reports series n? 91; Vienne, ST1/Doc/10/91, $214 \mathrm{pp}$

A.I.E.A. - 1970 - Isotope Hydrology, Proceedings of a Sympostum, Vienna 9 - 13 March, STl/PUB/255,918 pp.

A.I.E.A. - $1974-$ isotope Techniques in groundwater Hydrology. Proceedings of a symposium, Vienna, $11-15 \mathrm{March}, \mathrm{STI} / \mathrm{PUB} / 373$, vol, I: 504 pp., vol. H: $499 \mathrm{pp}$

ANDERSON, D.H. e HAWKES, M.E, - I958 - Relative Mobility of the common elements in weathering of some schist and granite areas. Geoch. and Cosmoch. Acta, vol. 14, pp. 204-10

BOATO, G. - 1960 - Isotope fractionation processes in nature. Summer course on Nuclear Geology, Varenne, pp. 129-149.

BRICKER, O.P. e GARRELS, R.M. - 1967 - Mineralogic Factors in Natural equilibria. Principles and Application of Water chemistry. John Wiley et Sons, N.Y., pp. 449-469.

CAMERON, J.F - - 1967 - Strvey of systems for concentration and low background counting of tritium in water. A.I.E.A., Radioactive dating and ne thod of low level counting, Monaco, 2 - 20 March 1967, p. 543.

CASTANY, G. - 1967 - Traité pratique des eaux souterraines. Dunod, Paris.

DAMON, P.E., LONG, A. e WALLICK, E.I. - 1972 - Dendrochoronologic calibration of the carbon 14 time scale. 8th Int. Conf. on radio, carbon dating, Wellington, New Zeland, pn. A $29-43$

DAVIS, G.H., MEYER, G.L. e YEN, C.K. - 1968 - Isotope Hydrology of the
Artesian aquifers of the Styrian Basin, Austria. Steirische Beiträge zur Hydrogeol, Graz (1968).

DAEE - 1974 - Estudos de Águas subterrâneas - V. 2.

DAEE - 1974 - Estudos de Aguas subterrâneas - V. 2.
DROST, W., MOSER, H., NEUMAIER, F. e RAUERT, W. - 1973 - Méthodes isotopiques en Hydrologie. Commission des Communautés Européennes, Cahier d'information du bureatu. EURISOTOP, Série monographie 16.

DYCK, W - 1968 - The geologic survey of Canada tadiocarbon dating laboratory. Paper 66-45. Geol. Sur. of Canada.

FETH, I.H., ROBERSON, C.E. e POLZER, W.L. - 1964 - Sources of mine ral constituents in water fron granitic rocks Sierra Nevada, California and $\mathrm{Ne}$ vada, U.S.G.S. Wa. Supp. Pap. 15351,70 po.

FLORKOWSKI, T. e JOB, C. - 1969 - Origin and underground flow time of thermal waters in crystalline Basement complexes. Steirisch Beitráge zur Hydrogeol., pp. 37-50.

GARRELS, R.M. - 1967 - Genesis of some groundwaters from Igneous Rocks. Research in Geochemistry, vol. q, John Wiley and Sons Inc., N.Y.

GARRELS, R.M. - 1975 - An overview of tow temperature water - mineral relations. Advisory group on the lnterpretation of Environmental Isotope and Hydrochemical data in Groundwater. Hydrology, I.A.E.A., Vienna.

GARRELS, R.M. C MACKENZIE, IF.T. - 1967 - Origin of the chemical compositions of some springs and Lakes. Equilibrium concepts in Natural Water Systems. Am. Chem. Soc. Publ., pp. 222-242.

GAT, J. - 1971 - Comments on the stable isotope method in regional ground water investigations. Wat. Res. vol. 7, n.' 4, pp. 980-93. 